\title{
Geochemical assessment of farmland ecosystems in the Yangtze River Basin, China
}

\author{
TAO YU ${ }^{1}$, ZHONGFANG YANG ${ }^{2}$, QINGYE HOU ${ }^{2}$, XUEQI
} $\mathrm{XIA}^{2}$, HAIYAN FENG ${ }^{2}$

${ }^{1}$ School of Science, China University of Geoscienecs, Beijing, China.(Email: yutao@cugb.edu.cn)

${ }^{2}$ School of Earth Sciences and Resources, China University of Geoscienecs, Beijing, China.

In farmland ecosystems, cultivated soil is the core of the elemental chemical cycle of the surficial geochemistry system.

At the regional scale, the factors affecting the soil element content of the cultivated layer are mainly the increase in content caused by fertilization, irrigation, and atmospheric wet and dry deposition, and the absorption of crops, infiltration of rainfall, runoff, and the sublimation of elements from solids to gas ${ }^{[1]}$. The content of soil elements decreases, and the trend of soil element content changes depends on the positive and negative net input fluxes of soil elements and the magnitude of the values caused by the above factors.

This study analyzes the effects of atmospheric wet and dry deposition (AWDD), fertilization, and irrigation on the content of element in the cultivated layer soil in the farmland ecosystem of the Yangtze River Basin in China.

According to the analysis of the annual fluxes of heavy metal elements in the AWDD, it can be seen that, except for elements such as potassium, calcium, magnesium, and nitrogen in the middle and upper reaches of the Yangtze River, the deposition fluxes of other elements are relatively small. At the same time, the deposition fluxes of various elements in the lower Yangtze River region are relatively high, especially for heavy metal elements, which are significantly higher than in other regions.

The main input paths of cadmium and lead elements in the Yangtze River Basin are AWDD which accounts for most of the total flux. The input of arsenics element is mainly the AWDD and irrigation water. The input flux of mercury in the lower reaches of the Yangtze River is dominated by AWDD, but in the upper and middle reaches of the Yangtze River, it is dominated by fertilizer input and irrigation water input.

In general, the annual input flux of heavy metals is in good agreement with the degree of industrial and mining development. Additionally, the authorities need to improve various environmental policies and reduce the total input of heavy metals as much as possible.

[1] Yu et al. (2014) Journal of Geochemical Exploration 139, 97-108. 